\title{
CONTRIBUIÇÕES DA LEI DE ACESSO À INFORMAÇÃO PARA O AVANÇO DA TRANSPARÊNCIA NO BRASIL
}

CONTRIBUTIONS OF THE ACCESS TO INFORMATION

LAW FOR THE ADVANCE OF TRANSPARENCY IN BRAZIL

Antonio João de Oliveira Vianna Junior

Mestre em Administração pelo PPGA/Universidade Federal Fluminense (UFF).

E-mail: viannajunior09@gmail.com.

\section{Júlio César Andrade de Abreu}

Doutor em Administração pela UFBA e Professor Adjunto da Universidade Federal Fluminense (UFF).

E-mail: jandrade0@gmail.com.

\section{Elen Maiara dos Santos Reis Ramos}

Mestranda em Administração pelo PPGA/Universidade Federal Fluminense (UFF).

E-mail: elenmreis@gmail.com.

\section{Sabrina Aparecida Pereira Bernardes}

Graduanda em Administração Pública pela Universidade Federal Fluminense (UFF).

E-mail: sabrinabernardes@idd.uff.br. 


\section{RESUMO}

Considerando a Lei de Acesso à Informação (LAI) como um referencial legal de institucionalização da transparência no âmbito público e uma ferramenta que viabiliza a democratização do acesso à informação, é inevitável a reflexão acerca de como se desenvolvem as pesquisas científicas sobre esta relevante temática. O presente trabalho tem como objetivo apresentar um panorama da produção científica sobre a $L A l$, tendo como premissa o consequente estreitamento das relações entre o governo e a sociedade através do advento da internet e das Tecnologias da Informação e Comunicação (TICs). A metodologia desenvolvida nesta pesquisa se ateve a uma pesquisa bibliométrica através de busca online em portais das bases de dados da ANPAD, Spell e SciELO, no período de 2011 a 2018. Como conclusão, observouse, principalmente, uma grande variância no número de publicações durante os anos, mesmo após quase sete anos da promulgação da lei; no entanto, o número de citações é relevante, o que mostra um certo crescimento na busca pelo aprofundamento do tema, mesmo que determinadas pesquisas não estejam publicadas em tais bases utilizadas neste trabalho.

Palavras-chave: Lei de acesso à informação. Transparência. Democratização da informação. TICs.

\section{ABSTRACT}

Considering the Law on Access to Information (LAI) as a legal framework for the institutionalization of transparency in the public sphere and a tool that facilitates the democratization of access to information, it is inevitable to reflect on how scientific research on this relevant issue is developed. The present work aims to present a panorama of the scientific production on LAl, based on the consequent narrowing of relations between government and society through the advent of the Internet and Information and Communication Technologies (ICTS). The methodology developed in this research was based on a bibliometric survey through online portal search of ANPAD, Spell and SciELO databases, from 2011 to 2018. As a conclusion, a large variance was observed in the number of publications during even after nearly seven years of enactment of the law; however, the number of citations is relevant, which shows a certain growth in the search for the topic, even if certain researches are not published in such bases used in this work.

Keywords: Law of access to information. Transparency. Democratization of information. TICs. 


\section{INTRODUÇÃO}

A distinta evolução nos modelos de administração pública desenvolvidos pelos governantes brasileiros proporcionou uma notória ampliação da participação da sociedade nas ações governamentais, seja através de ferramentas de controle social ou na fiscalização de ações dos servidores públicos, sejam eles do executivo, legislativo ou judiciário.

A ocorrência de uma articulação transparente da sociedade com os atores públicos, governamentais ou não, viabiliza a institucionalização das políticas públicas e proporciona a efetivação da redução das desigualdades da sociedade e o consequente progresso da inclusão social e obtenção e resgate de direitos (SMANIO; NUNES, 2016). Os mesmos autores indicam ainda que a implementação da transparência e da participação social consolida-se como alicerce para a elaboração, acompanhamento e aplicação de políticas públicas em um Estado Democrático de Direito.

Nesse sentido, percebe-se que o uso de tecnologias de informação e comunicação (TICs) e de uma linguagem cidadã, menos insulada e técnica, são meios que facilitam a interação governo-sociedade num contexto democrático de transparência pública. As TICs representam uma política de governo eletrônico (e-gov), no qual serviços e informações são oferecidos e acessados através da Internet (GUIMARÃES; MEDEIROS, 2005). O surgimento e desenvolvimento dos meios de TICs seguem influenciando o processo de reestruturação dos sistemas políticos europeus, e os seus elementos de comunicação e interação permitem que os processos possam evoluir no sentido de melhorar o funcionamento do sistema democrático e ainda para novos modelos de democracia (COLOMBO, 2006).

Em consequência da evolução das relações sociais advindas do constante avanço tecnológico mundial, a internet se faz como importante instrumento de interação entre a sociedade e o Estado. Cabe destacar que 64,7\% da população brasileira acima de 10 anos de idade tem acesso à internet por meio de dispositivos eletrônicos (IBGE, 2016), fator este que propicia uma evidência de fomento e exploração de sistemas que implementam e incentivam formas digitais de interação entre os poderes e os cidadãos. De acordo com Lopes e Sant'Ana (2013), avanços substanciais são proporcionados pela Web na esfera social, merecendo destaque a viabilização de recursos para a distribuição de informações governamentais, proporcionando assim uma consequente expansão da transparência e da participação cidadã no setor público.

Segundo Lemos et al. (2004), os portais governamentais na internet têm a função de demonstrar de forma didática e clara o conteúdo viabilizado pelos gestores públicos para os cidadãos, devido ao fato de o ambiente virtual ser propício para acúmulo e acesso às informações, serviços e dados de atividades econômicas e políticas locais. Os portais de governo são considerados como o dispositivo substancial que concede a interação do público através da internet (BRAGATTO, 2007; AKUTSU; PINHO, 2002). 
Neste contexto, torna-se inegável a referência à implementação da Lei de Acesso à Informação (LAI), lei n 12.527 de 18 de novembro de 2011, como um marco da transparência e da facilitação do controle social no setor público nacional. Embora carente de aperfeiçoamento, a LAl obriga os órgãos públicos integrantes dos três poderes à adoção de aspectos que viabilizam a obtenção e divulgação de informações a quaisquer interessados.

A LAl delimita uma nova importância dada pelo governo brasileiro à ampliação da transparência na gestão pública em todas as esferas. A referida normativa é mais um instrumento legal que visa a ampliar o poder do cidadão, que pode atuar de forma mais direta e participativa na administração pública. Esse incremento na participação da coletividade, com acesso quase que irrestrito às informações produzidas pelos agentes estatais, reforça o desenvolvimento de uma cultura de acesso em oposição a uma cultura de segredo (CGU, 2011).

Diante deste cenário, após quase sete anos de promulgação da lei, mostra-se a seguinte questão: De que forma se apresenta a produção de artigos científicos acerca da temática dos efeitos da LAI no Brasil no período entre 2011 e 2018? Para respondê-la, esta pesquisa consultou as bases de dados SciELO, Anpad e Spell, em busca de artigos publicados que abordaram a questão e evidenciaram o assunto correlacionado. Assim sendo, o objetivo desta pesquisa é apresentar um panorama da produção científica de artigos realizados sobre a Lei de Acesso à Informação, bem como destacar as principais conclusões dos artigos mais citados - considerados como mais relevantes.

A presente pesquisa se justifica pela abordagem panorâmica sobre uma temática atual e pertinente que se identificou como um marco no avanço do controle social por intermédio da inovação tecnológica. A relevância baseia-se ainda na ausência de êxito na busca em bases estruturadas de dados (SciELO, SPELL, OPUS, Web of Science e Google Acadêmico) de pesquisas bibliométricas abordando o assunto específico em questão no Brasil, o que evidencia um lapso oportuno para a exploração do conhecimento no assunto e uma possibilidade de direcionar estudos futuros em aspectos ainda pouco explorados.

O presente artigo encontra-se dividido em cinco partes além desta introdução, seguido por uma fundamentação teórica, método de pesquisa, análise dos resultados, conclusões e referências.

\section{FUNDAMENTAÇÃO TEÓRICA}

Aquisão resgatados, de forma sucinta, os principais conceitos oriundos do histórico da implementação da Lei de Acesso à Informação no Brasil e no mundo. 


\subsection{O ACESSO À INFORMAÇÃO NO MUNDO}

Nos últimos 30 anos, pôde ser observada uma verdadeira revolução no direito à informação, que é comumente compreendido como o direito de acesso à informação mantida por órgãos públicos (MENDEL, 2009). Mudanças paradigmáticas, como a transição de diversos países para o regime democrático, as reformas administrativas ocorridas e os avanços nas tecnologias de informação e comunicação, têm contribuído para estreitar as relações entre Estado e sociedade possibilitando assim uma maior participação popular e controle social.

O direito de acesso à informação constitui um direito universal reconhecido por organismos da comunidade internacional, como a Organização das Nações Unidas (ONU), e previsto no artigo $19^{\circ}$ da Declaração Universal de Direitos Humanos, que garante o direito à liberdade de opinião e expressão a todo ser humano, incluindo o direito de procurar, receber e transmitir informações e ideias por quaisquer meios, independentemente de fronteiras.

O direito de obter informações está regulamentado constitucionalmente em alguns países. A primeira lei sobre direito de acesso à informação de que se tem notícia foi promulgada na Suécia em 1766, a Lei de Liberdade de Imprensa, sendo uma lei muito importante para a cultura política e social deste país.

Em sua obra, Mendel (2009) cita outros exemplos de disposições abrangentes sobre o direito à informação em diferentes regiões do mundo, incluindo a Bulgária (Constituição de 1991, Artigo 41), Estônia (Constituição de 1992, Artigo 44), Hungria (Constituição de 1949, Artigo 61[1]), Lituânia (Constituição de 1992, Artigo 25), Malawi (Constituição de 1994, Artigo 37), México (Constituição de 1917, Artigo 6), Filipinas (Constituição de 1987, Artigo III), Polônia (Constituição de 1997, Artigo 61), Romênia (Constituição de 1991, Artigo 31), África do Sul (Constituição de 1996, Seção 32) e Tailândia (Constituição de 2007, Seção 56). Ainda segundo o autor, a maioria das leis sobre direito à informação atribui uma obrigação aos órgãos públicos de publicar informações de forma proativa ou rotineira, independentemente de requisições específicas (MENDEL, 2009, p. 5).

Na América Latina, a Colômbia foi o país pioneiro ao implementar o Código de Organização Política e Municipal de 1888, que permitia aos indivíduos solicitar documentos sob o controle de órgãos governamentais ou contidos em arquivos do governo. Posteriormente, nota-se que os EUA que aprovaram uma lei de direito à informação em 1967, que foi seguida por legislação na Dinamarca (1970), Noruega (1970), França (1978), Países Baixos (1978), Austrália (1982), Canadá (1982) e Nova Zelândia (1982) (MENDEL, 2009, p. 26). 
Observa-se que alguns países, provavelmente devido à ausência de um ambiente democrático e transparente, encontraram dificuldades em implementar dispositivos de lei que consolidassem o direito de acesso à informação.

Na América Latina, por sua vez, o atraso na implantação de leis ou regras que possibilitasse o acesso a documentos que antes estavam nas mãos de instituições públicas e autoridades só fui possivel a partir da década de 1980, com o fim das ditaduras militares que persistiram no continente por um longo período. Apenas no século XXI que maior parte da América Latina conseguiu aprovar leis de acesso à informação (MOTA; SOUZA, 2014, p. 3).

Na história da administração pública brasileira, os frequentes casos de corrupção, nepotismo e ineficiência na gestão estatal estão presentes desde o império (LORENTE, 2016). A década de 80 foi um período de mudanças significativas e é caracterizada por um movimento intenso de luta pela ampliação dos mecanismos institucionais de diálogo entre o Estado brasileiro e os cidadãos, o que culminou na materialização do fim da ditadura e a realização das eleições diretas para presidente. A Constituição Federal de 1988, além de marcar o início da consolidação da democracia no Brasil, foi o primeiro normativo a prever o direito ao acesso à informação e destacar o princípio da publicidade e eficiência da administração pública. Atualmente, o acesso à informação tem sido apontado como uma ferramenta de controle social e combate à corrupção em todo o mundo.

\subsection{CONCEITOS HISTÓRICOS DA LEI DE ACESSO À INFORMAÇÃO NO BRASIL}

No Brasil, apesar de existirem exceções pontuais que impõem limites ao princípio da publicidade previsto na Constituição Federal de 1988, tal princípio tem como principal objetivo a divulgação de informações sobre as ações realizadas pela administração pública em prol do interesse social (REIS, 2016).

A transparência é um dos princípios da governança pública derivado do princípio constitucional da publicidade que objetiva o acesso, o controle e a clareza das informações prestadas pelos entes públicos de modo a garantir o exercício da 
democracia, o aperfeiçoamento da gestão pública e o combate à corrupção no setor público (REIS, 2016, p. 26).

A concretização do princípio da transparência no Brasil teve início a partir da promulgação da Lei Complementar $n^{\circ}$ 101, que entrou em vigor em 4 de maio de 2000. A chamada Lei de Responsabilidade Fiscal (LRF) representa um instrumento para auxiliar os governantes a gerir os recursos públicos dentro de um marco de regras claras e precisas, aplicadas a todos os gestores de recursos públicos e em todas as esferas de governo, relativas à gestão da receita e da despesa públicas, ao endividamento e à gestão do patrimônio público.

Posteriormente, em 2009, a Lei Complementar n 131 de 2009, que acrescentou dispositivos à Lei de Responsabilidade Fiscal, proporcionou a concretização da garantia do pleno conhecimento e acompanhamento da sociedade, em tempo real, de informações pormenorizadas sobre a execução orçamentária e financeira através de meios eletrônicos de acesso público facilitados pelos mecanismos de governo eletrônico.

Apesar de a Constituição brasileira de 1988 já prever o acesso às informações públicas, precisou de mais de duas décadas para a efetiva regulamentação deste dispositivo. Segundo Jardim (2013), a primeira regulamentação deste preceito constitucional se deu por meio de todo o capítulo V da Lei de Arquivos (Lei 8.159 de 8 de janeiro de 1991), que era dedicado ao "acesso e sigilo dos documentos públicos".

As discussões iniciais sobre a implementação de uma Lei de Acesso à Informação no país tiveram início em 2005 no Conselho de Transparência, atual Conselho de Transparência Pública e Combate à Corrupção. Em 2006, a então Controladoria Geral da União apresentou o primeiro anteprojeto sobre acesso à informação ao Conselho de Transparência. Já em 2009, o Poder Executivo apresentou ao Congresso Nacional o Projeto de Lei n 5.228 regulando o acesso às informações públicas. Foi também em 2009 que o Projeto de Lei n 219 de 2003 foi anexado ao Projeto de Lei n 5.228 e este, posteriormente, foi convertido na Lei nº 12.527 de 2011.

Com a consolidação da Lei $n^{\circ}$ 12.527, Lei de Acesso à Informação (LAI), foram estabelecidos procedimentos a serem observados pelos três Poderes assim como por todas as esferas da União, Estados, Distrito Federal e Municípios, visando a garantir o acesso às informações públicas. A LAl passou a vigorar em 16 de maio de 2012 e com isso o Brasil passou a ser o $91^{\circ}$ país a implementar uma lei de acesso à informação.

A LAl garante à sociedade o acesso às informações públicas na forma de transparência ativa e passiva. A transparência ativa é fornecida independente de solicitação, divulgadas, principalmente, nos 
sítios eletrônicos do governo na internet. Já a transparência passiva é evidenciada quando as informações são disponibilizadas mediante um pedido de informação específico realizado por pessoas físicas ou jurídicas desde que as informações solicitadas não estejam sujeitas a restrição de acesso por conter informações pessoais, estejam classificadas como sigilosas ou protegidas por outras legislações vigentes.

Mesmo seis anos após ter entrado em vigor, a LAl ainda possui diversos desafios em sua implementação. Com isso, mostra-se essencial a produção de pesquisas sobre políticas e práticas informacionais que favoreçam o uso social da informação produzida pelo Estado nos marcos democratizantes da Lei de Acesso à Informação Pública, conforme argumenta Jardim (2013).

\subsection{A LEI DE ACESSO À INFORMAÇÃO E OS MECANISMOS DE GOVERNO ELETRÔNICO}

O desenvolvimento dos mecanismos de tecnologia da informação e comunicação tem sido incorporado pelos setores da administração pública contribuindo, assim, para o processo de reestruturação da gestão pública, através de sistemas de governo eletrônico que visam democratizar o acesso às informações públicas por meio da efetivação de boas práticas de governança.

O objetivo almejado pelo modelo de administração da Nova Gestão Pública, iniciado na década de 90, era tornar a administração pública eficiente, tal como o setor privado, de modo a otimizar os serviços. Com isso, tais preceitos vão ao encontro dos propósitos dos governos em utilizar as TICs, fazendo surgir, a partir disso, o que os teóricos convencionaram chamar de governo eletrônico (e-gov) (SANTOS; BERNARDES; ROVER, 2012).

O conceito de governo eletrônico surgiu no Brasil a partir dos anos 90. De acordo com Cunha (2010), em 1995, uma portaria conjunta entre os ministérios das Comunicações e da Ciência e Tecnologia criou a figura do provedor de acesso privado, surgindo assim os primeiros domínios gov.br e as primeiras páginas governamentais na internet.

Segundo Prado e Loureiro (2008):

O governo eletrônico surge em meio a um contexto caracterizado de um lado pelos movimentos de reforma do Estado e emergência de temas como accountability e transparência e, de outro, pelo surgimento de novas tecnologias na área da informática que permitiram a criação de sistemas de informação mais abrangentes, assim como o desenvolvimento vertiginoso da microinformática e da internet (PRADO; LOUREIRO, 2008, p. 358). 
No ano de 2000, através do Decreto Presidencial de 3 de abril de 2000, foi instituído o Grupo de Trabalho Interministerial para examinar e propor políticas, diretrizes e normas relacionadas com as novas formas eletrônicas de interação. Assim, deu-se o início do Programa de Governo Eletrônico do Estado brasileiro.

A Lei de Acesso à Informação trouxe, em seu artigo 8 , parágrafo segundo, a necessidade de que os órgãos e entidades públicas utilizem todos os meios e instrumentos legítimos de que dispuserem para disponibilização de informações, sendo obrigatória a divulgação em sítios oficiais da rede mundial de computadores (internet). Com isso, os órgãos da administração pública foram obrigados a implementar mecanismos para facilitar o acesso e disponibilização das informações através dos sites e portais institucionais.

Com o advento do Novo Serviço Público (NSP), surge a necessidade de promover e reafirmar os valores da democracia, da cidadania e do interesse público, conforme enfatizado por Denhardt e Denhardt (2003). Segundo Abreu, Helou e Fialho (2013), as características apresentadas pelo NSP fundamentamse em valores compartilhados e interesses comuns obtidos por meio do diálogo e do engajamento dos cidadãos e são vistas como uma extensão da cidadania.

A Lei de Acesso à Informação surge como instrumento de amparo à participação e ao controle social, devido à possibilidade de ampliação da transparência e a consequente aquisição de conhecimento por parte de quem faz uso das informações públicas, como aspirado pelos conceitos propostos pelo NSP. Cabe ressaltar que o acesso e, também, a possibilidade de inteligibilidade da informação constituem requisitos indispensáveis para a construção de uma democracia participativa e do controle social efetivo, sendo assim, os mecanismos de governo eletrônico se tornam essenciais por possibilitar também maior facilidade na obtenção de informações públicas.

\section{METODOLOGIA DE PESQUISA}

Este estudo, de cunho descritivo, utilizou como metodologia a coleta de dados através de um levantamento documental por meio de consulta online. Buscou-se identificar os artigos relacionados ao tema da Lei de Acesso à Informação disponíveis no repositório de eventos da Associação Nacional de PósGraduação e Pesquisa em Administração (ANPAD) e nas bases de dados Scientific Electronic Library Online (SciELO) e Scientific Periodicals Electronic Library (SPELL).

Visando a obtenção de resultados amplos em cada base de dados pesquisada, foi utilizado o termo "Lei de Acesso à Informação" no período de 2011, limite inferior da base de dados da ANPAD, a 2018. De 
modo a atender o objetivo da bibliometria voltada para a área de estudo pretendida, foram filtrados os resultados dentro da área de Administração e afins.

Uma bibliometria é identificada por meio da aplicação de técnica quantitativa e estatística de medição dos índices de produção e propulsão do conhecimento científico, da mesma maneira que a demografia ao enumerar a população; ela aparece no início do século XX, como reflexo da necessidade do estudo e da avaliação das atividades de produção e comunicação científica (FONSECA, 1986).

A partir de uma listagem inicial, foram encontrados, na base de dados da ANPAD, na qual é possivel buscar trabalhos publicados nos eventos da mesma, apenas 3 artigos como resultado. Na base de dados da SciELO obteve-se como resultado da pesquisa 20 artigos e na base de dados SPELL 26 artigos. Posteriormente foram excluídos os artigos que se encontravam em duplicação em duas ou mais bases, assim como aqueles que fugiam do escopo de trabalho, a maior parte utilizando a LAl como meio de acesso aos dados para produção do artigo, restando assim uma consolidação de trinta artigos para análise. Através deste escopo selecionado foi possivel analisar os artigos pelo número de publicações por ano em cada base de dados, pelas dimensões das abordagens realizadas, pelos autores mais prolíferos e pela quantidade de citação de cada artigo.

\section{ANÁLISE DOS RESULTADOS}

O levantamento realizado buscou identificar pesquisas empíricas que versem sobre a Lei nº 12.527 de 2011, a chamada Lei de Acesso à Informação, que regula o acesso à informação, direito já previsto na Constituição Federal de 1988. A busca foi realizada nas bases de dados Scientific Periodicals Electronic Library (Speel), Scientific Eletronic Library Online (Scielo) e no repositório dos artigos apresentados em eventos organizados pela Associação Nacional de Pós-Graduação em Administração (ANPAD). Juntas, essas bases de dados cobrem os principais periódicos brasileiros.

O período de análise compreende os anos de 2011, data de implementação da LAl, até o presente ano, 2018. As buscas foram orientadas pela pesquisa dos termos: "Lei de acesso à informação", aplicada a qualquer campo disponivel nas ferramentas de buscas das bases. Como resultados, foram listados inicialmente 49 publicações. A partir daí, buscou-se realizar uma leitura dos resumos dos artigos da lista inicial com o fim de verificar se o contexto das publicações realmente se relacionava com tema proposto, bem como excluir os artigos duplicados, existentes em mais de uma base, finalizando a relação objetiva desta pesquisa com 30 publicações.

A Tabela 1 mostra o número de publicações agrupadas por base de dados e ano da publicação. 


\section{Gestãoe \\ Desenvolvimento}

e-ISSN: 2446-6875

p-ISSN: $1807-5436$

Tabela 1: Número de publicações por ano e por base de dados

\begin{tabular}{l|cc|cc|cc|ccc}
\hline \multicolumn{1}{c|}{ Base de dados } & $\mathbf{2 0 1 1}$ & $\mathbf{2 0 1 2}$ & $\mathbf{2 0 1 3}$ & $\mathbf{2 0 1 4}$ & $\mathbf{2 0 1 5}$ & $\mathbf{2 0 1 6}$ & $\mathbf{2 0 1 7}$ & $\mathbf{2 0 1 8}$ & Total \\
\hline ANPAD & 0 & 0 & 0 & 1 & 0 & 2 & 0 & 0 & 3 \\
\hline SciELO & 0 & 0 & 1 & 1 & 1 & 1 & 1 & 1 & 6 \\
\hline SPELL & 1 & 1 & 1 & 4 & 3 & 7 & 3 & 1 & 21 \\
Total geral de artigos por ano & $\mathbf{1}$ & $\mathbf{1}$ & $\mathbf{2}$ & $\mathbf{6}$ & $\mathbf{4}$ & $\mathbf{1 0}$ & $\mathbf{4}$ & $\mathbf{2}$ & $\mathbf{3 0}$ \\
\hline
\end{tabular}

Fonte: Elaborado pelos autores a partir dos dados coletados nas respectivas bases de dados.

Nos primeiros anos, de 2011 a 2013, foram apenas 4 publicações, sendo 13\% dos estudos analisados; de 2014 a 2016 foram 20 artigos, totalizando 68\% das publicações; e no período final analisado, de 2017 a setembro de 2018, houve uma queda nas publicações, totalizando 6 publicações, que correspondem a $19 \%$ dos estudos analisados. Percebe-se que houve um aumento no número de publicações sobre a Lei de Acesso à Informação no período de 2014 a 2016 e tal fato deve-se principalmente ao aumento de estudos focados na avaliação e no monitoramento do cumprimento dos requisitos da Lei pelos órgãos da administração pública.

De maneira sucinta, pode-se relacionar as publicações analisadas em cinco dimensões:

Figura 1. Dimensões das Publicações sobre a Lei de Acesso à Informação

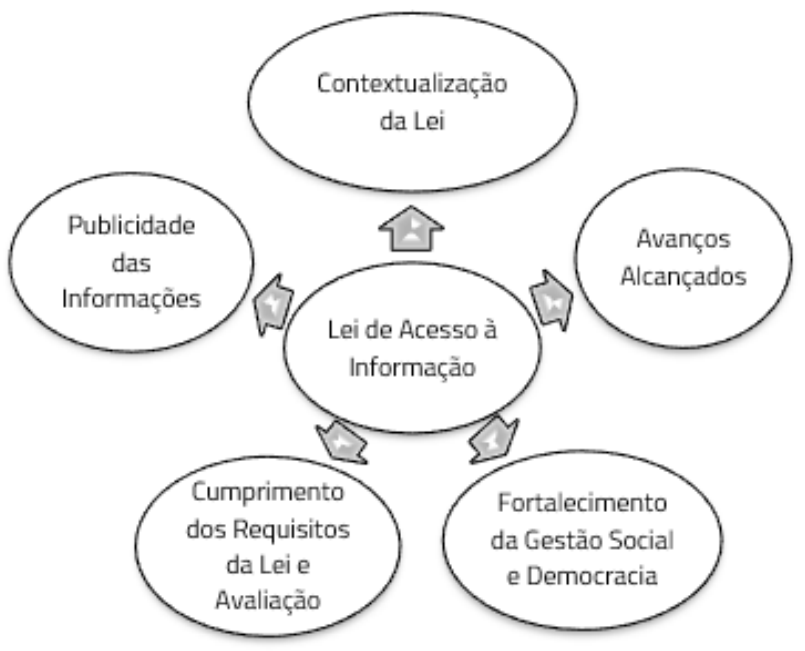

Fonte: Elaboração dos autores. 


\section{Gestãoe \\ Desenvolvimento}

e-ISSN: 2446-6875

p-ISSN: $1807-5436$

Conforme ilustrado através da Figura 1, buscou-se categorizar os artigos selecionados baseandose nas dimensões e objetivos aplicados, selecionados e classificados após leitura integral dos trabalhos. A partir de então, foi construída a Tabela 2, na qual evidencia-se a quantidade e o percentual de artigos por categoria.

Tabela 2: Número de publicações por dimensões

\begin{tabular}{l|ll|}
\hline \multicolumn{1}{c|c}{ Dimensões } & N de artigos & \multicolumn{1}{c|}{ Percentual (\%) } \\
\hline Contextualização da Lei & 5 & $17 \%$ \\
\hline Avanços Alcançados & 3 & $10 \%$ \\
\hline Fortalecimento da Gestão Social e Democracia & 4 & $13 \%$ \\
\hline Cumprimento dos Requisitos da Lei / Avaliação & 17 & $57 \%$ \\
\hline Publicidade das Informações & 1 & $3 \%$ \\
Total geral de artigos & $\mathbf{3 0}$ & $\mathbf{1 0 0} \%$ \\
\hline
\end{tabular}

Fonte: Elaborado pelos autores.

Do total da amostragem de publicações analisadas, 17\% dedicam-se à contextualização da lei, $10 \%$ aos avanços alcançados com a implementação da lei, 13\% ao fortalecimento da gestão social e da democracia, 57\% ao cumprimento dos requisitos da Lei através de avaliações e 3\% à necessidade de publicidade das informações. Na maioria dos artigos, o cumprimento dos requisitos previstos na Lei é tido como consequência da transparência.

No que tange à produção científica de artigos, verifica-se uma ampla diversidade de autores, cabendo destacar Fabiano Maury Raupp e José Antonio Gomes de Pinho, que se identificam como os autores mais prolíferos, possuindo dentro do escopo analisado dois artigos em coautoria.

A Tabela 3 identifica as publicações mais citadas com base no Google Acadêmico, evidenciando assim as fontes mais relevantes para o estudo da área. 
Tabela 3: Relação de artigos com maior número de citações

\begin{tabular}{l|l|}
\hline \multicolumn{1}{c|}{ Artigo } & \multicolumn{1}{c|}{ Nº de Citações $^{-1}$} \\
$\begin{array}{l}\text { Ranking das prefeituras da região Sul do Brasil: uma avaliação a partir de critérios } \\
\text { estabelecidos na Lei de Acesso à Informação }\end{array}$ & 25 \\
\hline $\begin{array}{l}\text { Aconstrução dalei de acesso à informação pública no Brasil: desafios na implementação } \\
\text { de seus princípios }\end{array}$ & 18 \\
\hline Observância da lei de acesso à informação pelas autarquias federais do Brasil & 12 \\
\hline Acesso à Informação e Ação Comunicativa: novo trunfo para a Gestão Social & 11 \\
\hline $\begin{array}{l}\text { Prestação de contas nos portais eletrônicos de Assembleias Legislativas: um estudo } \\
\text { após a Lei de Acesso à Informação }\end{array}$ & 11 \\
\hline
\end{tabular}

Fonte: Elaborado pelos autores.

Os artigos mais citados refletem ainda as discussões atuais de maior interesse no setor público, sendo elas: os efeitos da aplicação da lei, a contextualização da lei no sentido da necessidade de uma política pública efetiva e necessária para gestão social e a avaliação das informações sobre prestação de contas presentes nos sítios eletrônicos de órgãos da administração pública.

No sentido de apresentar um panorama das principais produções científicas analisadas sobre a temática da Lei de Acesso à Informação, foram elencadas, em ordem cronológica, as principais contribuições e resultados dos artigos mais relevantes que compõem a amostra desta pesquisa. A relevância considerou, dentro do escopo dos 30 artigos identificados, os critérios de quantidade de citação e credibilidade do periódico de publicação dentro de cada ano, no período entre 2011 e 2018.

Inicialmente, Paes (2011) consolidou em sua pesquisa, que fora baseada em um estudo comparativo na experiência norte-americana e no México, o entendimento da essencialidade da LAl como normativo subsidiário à melhoria e ao desenvolvimento das condições de acesso à informação no Brasil. Entretanto, a autora indicou ainda a existência de obstáculos ao progresso almejado, identificados pela burocracia administrativa existente, o que evidencia uma necessidade de implementação de políticas públicas que efetivem de fato o direito à informação por meio de ações governamentais.

No mesmo sentido, Angélico e Teixeira (2012) arremataram sua pesquisa direcionando a evidência da LAl como ferramenta de suporte da Gestão Social, viabilizando assim as relações democráticas e republicanas entre a Sociedade e o Estado. Observa-se que em virtude da pouca maturidade da existência da referida regulamentação de acesso à informação, as pesquisas nos dois primeiros anos de análise, 2011 e 2012, mostram-se pouco aprofundadas no caráter efetivo da aplicação, abordando, assim, dimensões mais contextualizadoras e de fortalecimento do Controle Social e dos laços democráticos. 
Já em 2013, Cavalcanti, Damasceno e Souza Neto realizaram um estudo acerca da implementação da LAI nas autarquias federais e obtiveram como resultado uma baixa representatividade de órgãos que cumpriam na íntegra as exigências legais, ressaltando alguns pontos em que mais de $90 \%$ da amostra não atendiam às normas estabelecidas. No mesmo sentido, Raupp e Pinho (2014) evidenciaram uma baixa capacidade de prestação de contas existente nas assembleias legislativas dos 27 estados Brasileiros, especificamente ainda devido ao pouco uso de portais governamentais para apresentação dos gastos públicos pelos deputados.

No que tange ao legislativo municipal, os mesmos autores, ainda, corroboraram a baixa aplicabilidade da LAl através de um estudo que revelou uma ausência de avanços por meio da manutenção das informações nos portais das câmaras municipais de 75 cidades do estado de Santa Catarina (Raupp e Pinho, 2015). Bernardes, Santos e Rover (2015) apontaram, através de pesquisa nas prefeituras da região Sul do Brasil, uma deficiência ainda mais substancial de efetivação da LAl, na qual identificou-se que apenas 8,35\% dos 479 municípios analisados apresentaram algum aspecto representativo da LAl em seus portais governamentais.

Nessa continuidade, Gama e Rodrigues (2016) concluíram, através de um estudo nas universidades federais, que não houve alterações significativas entre os dois primeiros anos de implementação da LAl, ressaltando a existência de demanda não correspondida por informações contábeis.

Em pesquisa mais atual, De Andrade e Raupp (2017) apontaram, ainda, a existência de lacunas não preenchidas no atendimento aos indicadores da LAl pelos portais da internet das câmaras municipais das cinquenta maiores cidades brasileiras, evidenciando, assim, uma oportunidade de reorganização da gestão aplicada às informações e da cultura organizacional no legislativo local. Ao encontro das pesquisas ressaltadas, Michener, Contreras e Niskier (2018) concluíram pela deficiência da implementação da LAI ilustrada pela insuficiência de indicadores de atendimento, exemplificados por estatísticas governamentais sobre pedidos de informação, compromissos com o atendimento à informação, plataformas peculiares para tramitação de pedidos de informação e setores de controle.

Os principais resultados encontrados nos estudos analisados revelam que, embora a Lei de Acesso à Informação se apresente como uma grande aliada dos cidadãos para cobrar a divulgação de informações relativas aos atos da administração pública, esta ainda carece de atenção por parte dos gestores e agentes públicos a fim de cumprir as exigências especificadas no texto legal, viabilizando assim uma maior transparência da gestão pública e uma interação mais efetiva com a sociedade. 


\section{CONSIDERAÇÕES FINAIS}

Este trabalho teve como objetivo averiguar a produção de artigos científicos acerca da temática dos efeitos da LAl no Brasil no período entre 2011 e 2018; para tanto, levantou 30 estudos realizados sobre a lei e verificou a abordagem dada a cada um, além de dispor de ano e autor. Foi observado que houve uma variação no quantitativo de publicações por ano, não apresentando um crescimento contínuo; o número de citações indicou os autores que mais se destacam no tema, mas, sobretudo, que há um número considerável destas, apontando o interesse pelo tema. Sobre a categorização, é possivel observar que a maior parte dos artigos se debruçam sobre a avaliação da LAl e verificam o cumprimento dos requisitos previstos pela mesma nos órgãos. Seguido pela contextualização, ou seja, exposição do processo de criação da lei, marco legal e implementação.

Os estudos em si mostraram que o arcabouço administrativo interfere na efetividade da lei, ou seja, na consolidação e qualidade das informações prestadas. Observa-se, ainda, certa resistência e até dificuldade no acompanhamento da evolução da internet pelo setor público e seu corpo técnico, principalmente nos municípios de pequeno porte, que, de acordo com alguns estudos encontrados, possuem portais mais defasados em relação aos de nível federal.

No mais, a LAl é uma evolução institucional inegável do acesso à informação, um caminho para o controle social e para o acompanhamento das ações dos agentes públicos, e a discussão desta pela academia se mostra indispensável de maneira a gerar feedback para seu aperfeiçoamento.

\section{REFERÊNCIAS}

ABREU, A. C. D.; HELOU, A. R. H. A.; FIALHO, F. A. P. Possibilidades epistemológicas para a ampliação da Teoria da Administração Pública: uma análise a partir do conceito do Novo Serviço Público. Cadernos EBAPE. BR, v. 11, n. 4, p. 608-620, 2013. Disponível em: <http://www.scielo.br/pdf/cebape/v11n4/09. pdf > Acesso em: 01 de set. de 2018.

ABRUCIO, F. L.; LOUREIRO, M. R. Finanças públicas, democracia e accountability: debate teórico e o caso brasileiro. In: BIDERMAN, Ciro; ARVATE, Paulo Roberto. Economia do setor público no Brasil. Elsevier, 2004.

AKUTSU, L.; PINHO, J. A. G. Sociedade da informação, accountability e democracia delegativa: investigação em portais de governo no Brasil. Revista de Administração Pública, v. 36, n. 5, p. 723-745, 2002. Disponivel em: <http://bibliotecadigital.fgv.br/ojs/index.php/rap/article/viewFile/6461/5045> Acesso em: 05 de set. de 2018. 
ANDRADE, R. G.; RAUPP, F. M. Transparência do Legislativo Local à Luz da Lei de Acesso à Informação: Evidências Empíricas a Partir dos Maiores Municípios Brasileiros. Desenvolvimento em Questão, v. 15, n. 41, p. 85-130, 2017. Disponível em: <http://www.spell.org.br/documentos/ver/47203>. Acesso em: 04 de set. de 2018 .

ANGÉLICO, F.; TEIXEIRA, M. A. C. Acesso à Informação e Ação Comunicativa: novo trunfo para a Gestão Social. Desenvolvimento em Questão, v. 10, n. 21, p. 7-27, 2012. Disponível em: <http://www.spell.org. br/documentos/ver/8958/acesso-a-informacao-e-acao-comunicativa--novo-trunfo-para-a-gestao-social>. Acesso em: 05 de set. de 2018.

BERNARDES, M. B.; SANTOS, P. M.; ROVER, A. J. Ranking das prefeituras da região Sul do Brasil: uma avaliação a partir de critérios estabelecidos na Lei de Acesso à Informação. Rev. Adm. Pública, Rio de Janeiro, v. 49, n. 3, p. 761-792, 2015. Disponivel em: <http://www.scielo.br/scielo.php?script=sci_arttext\&pid=S0034-76122015000300761\&lng=en\&nrm=iso >. Acesso em: 01 de set. de 2018.

BRAGATTO, R. Participação Democrática e Internet: Uma breve análise dos Websites dos Governos Federais dos quatro maiores Países Sulamericanos. 2007. Dissertação - Universidade Federal do Parana, Curitiba.

BRASIL. Constituição da República Federativa do Brasil, 1988. Disponível em: < http://www.planalto. gov.br/ccivil_03/constituicao/constituicao.htm>. Acesso em: 13 de set. de 2018.

. Decreto Presidencial de 03 de abril de 2000. Institui Grupo de Trabalho Interministerial para examinar e propor políticas, diretrizes e normas relacionadas com as novas formas eletrônicas de interação, Brasilia, DF, 03 abr. 2000. Disponível em: <http://www.planalto.gov.br/ccivil_03/DNN/2000/ Dnn8917.htm>. Acesso em: 13 de set. de 2018.

Lei Complementar n 101/2000, de 4 de maio de 2000.Estabelece normas de finanças públicas voltadas para a responsabilidade na gestão fiscal e dá outras providências. Disponível em: <http:// www.planalto.gov.br/ccivil_03/leis/LCP/Lcp101.htm>. Acesso em: 13 de set. de 2018.

Lei Complementar n 131/2009, de 27 de maio de 2009. Acrescenta dispositivos à Lei Complementar $n^{\circ} 101$, de 4 de maio de 2000, que estabelece normas de finanças públicas voltadas para a responsabilidade na gestão fiscal e dá outras providências, a fim de determinar a disponibilização, em tempo real, de informações pormenorizadas sobre a execução orçamentária e financeira da União, dos Estados, do Distrito Federal e dos Municípios. Disponivel em: <http://www.planalto.gov.br/ ccivil_03/leis/lcp/lcp131.htm>. Acesso em: 13 de set. de 2018. 
Lei $n^{\circ}$. 12.527/11, de 18 de novembro de 2011. Regula 0 acesso a informações previsto no inciso XXXIII do art. 50, no inciso II do § 30 do art. 37 e no § 20 do art. 216 da Constituição Federal; altera a Lei no 8.112, de 11 de dezembro de 1990; revoga a Lei no 11.111, de 5 de maio de 2005, e dispositivos da Lei no 8.159, de 8 de janeiro de 1991; e dá outras providências. Disponível em: < http://www.planalto.gov.br/ccivil_03/_ato2011-2014/2011/lei//12527.htm>. Acesso em: 12 de set. de 2017.

Lei $n^{\circ}$. 8.159, de 8 de janeiro de 1991. Dispõe sobre a política nacional de arquivos públicos e privados e dá outras providências. Disponível em: <http://www.planalto.gov.br/ ccivil_03/LEIS/L8159. htm>. Acesso em: 14 de set. de 2017.

Ministério da Transparência, Fiscalização e Controladoria Geral da União. Cartilha de Acesso à Informação pública: Uma introdução à Lei no 12.527, de 18 de novembro de 2011. Disponivel em: <http://www.acessoainformacao.gov.br/central-de-conteudo/ publicacoes/ arquivos/ cartilha acesso a informacao-1.pdf>. Acesso em: 02 de jul. de 2017.

CAVALCANTI, J. M. M.; DAMASCENO, L. M. S.; SOUZA NETO, M. V. Observância da lei de acesso à informação pelas autarquias federais do Brasil. Perspect. ciênc. inf., Belo Horizonte, v. 18, n. 4, p. 112-126, 2013. Disponivel em: <http://www.scielo.br/scielo.php?pid=S141399362013000400008\&script=sci_abstract\&tlng=pt>. Acesso em: 03 de set. de 2018.

CUNHA, M. A. Governo eletrônico no Brasil: avanços e impactos na sociedade brasileira. Pesquisa sobre o Uso das Tecnologias da Informação e da Comunicação no Brasil 2005-2009, p. 73, 2010.

COLOMBO, C. Innovación democrática y TIC, ¿ hacia una democracia participativa? Revista de Internet, derecho y política, n. 3, p. 7., 2006. Disponível em: <https://dialnet.unirioja.es/servlet/articulo?codigo=2119691 >. Acesso em: 03 de ago. de 2018.

DENHARDT, J. V.; DENHARDT, R. B. The New Public Service: serving, not steering. New York: M. E. Sharpe, 2003.

FONSECA, E. N. (Org). Bibliometria: teoria e prática. São Paulo: Cultrix, Ed. da USP, 1986.

GAMA, J. R.; RODRIGUES, G. M. Transparência e acesso à informação: um estudo da demanda por informações contábeis nas universidades federais brasileiras. Transinformação, Campinas, v. 28, n. 1, p. 4758, 2016. Disponivel em: <http://www.scielo.br/scielo.php?pid=S0103-37862016000100047\&script=sci_abstract\&tlng=pt>. Acesso em: 04 de set. de 2018. 
GUIMARÃES, T. A.; MEDEIROS, P. H. R. A relação entre governo eletrônico e governança eletrônica no governo federal brasileiro. Cadernos EBAPE.BR, Rio de Janeiro, v. 3, n. 4, 2005. Disponivel em: <http:// www.scielo.br/scielo.php?script=sci_arttext\&pid=S1679-39512005000400004>. Acesso em: 04 de ago. de 2018.

IBGE - Instituto Brasileiro de Geografia e Estatística. Pesquisa Nacional por Amostra de Domicílios Contínua. Rio de janeiro, 2016. Disponível em: <https://ww2.ibge.gov.br/home/estatistica/pesquisas/ pesquisa_resultados.php?id_pesquisa=149>. Acesso em: 11 de ago. de 2018.

JANET, D. V.; ROBERT, D. B. The new public service: serving, not steering. New York: Armonk, 2003.

JARDIM, J. M. A lei de acesso à informação pública: dimensões político-informacionais. 2013.

LEMOS, A.; MAMEDE, J.; NÓBREGA, R.; PEREIRA, S., MEIRELLES, L. Cidade, Tecnologia e Interface. Análise de Interfaces de Portais Governamentais Brasileiros. Uma proposta metodológica. Revista Fronteiras, v. VI, 117-136, 2004. Disponivel em: <http://revistas.unisinos.br/index.php/fronteiras/article/ view/6595>. Acesso em: 02 de set. de 2018.

LOPES, R. de C. C.; SANT'ANA, R. C. G. Percepção dos usuários sobre o processo de acesso a dados sobre saúde em sítios do Governo Federal. In: ENCONTRO NACIONAL DE PESQUISA EM CIÊNCIA DA INFORMAÇÃO - ENANCIB, 14., 2013, Florianópolis. Anais. Florianópolis: ANCIB, 2013. Disponível em: <http:// enancib2013.ufsc.br/index.php/enancib2013/XIVenancib/paper/viewFile/188/ 309>. Acesso em: 7 mar. 2015.

LORENTE, Vitória Marques. Corrupção no Brasil e estratégias de combate. Revista Brasileira de Estudos da Função Pública - RBEFP, Belo Horizonte, ano 5, n. 14, p. 203-257, maio/ago. 2016.

MENDEL, T. Liberdade de informação: um estudo de direito comparado. Unesco, 2009.

MICHENER, Gregory; CONTRERAS, Evelyn; NISKIER, Irene. Da opacidade à transparência? Avaliando a Lei de Acesso à Informação no Brasil cinco anos depois. Rev. Adm. Pública, Rio de Janeiro, v. 52, n. 4, p. 610-629, 2018. Disponivel em <http://www.scielo.br/scielo.php?script=sci_arttext\&pi$d=S 0034-76122018000400610 \&$ Ing=pt\&nrm=iso >. Acesso em: 19 de set. de 2018.

MOTA, M. A.; DE SOUZA, R. M. V. Lei de Acesso à informação na América Latina: Impactos na Produção de Jornal. XII Congreso de la Asociación Latinoamericana de Investigadores de la Comunicación (ALAIC). Lima: 2014. Disponivel em: <http://congreso.pucp.edu.pe/alaic2014/wp-content/uploads/2013/11/vGT18-Mota-de-Souza.pdf>. Acesso em: 13 de set. de 2018. 
PAES, E. B. A construção da lei de acesso à informação pública no Brasil: desafios na implementação de seus princípios. Revista do Serviço Público, v. 62, n. 4, p. 407-423, 2011.

PRADO, O.; LOUREIRO, M. R. G. Governo eletrônico e transparência: avaliação da publicização das contas públicas das capitais brasileiras. Revista Alcance, v. 13, n. 3, p. 355-372, 2008. Disponivel em: <http:// bibliotecadigital.fgv.br/dspace/handle/10438/2432>. Acesso em: 03 de set. de 2017

RAUPP, F. M.; PINHO, J. A. G. Prestação de contas no legislativo local antes e depois da lei de acesso à informação. Contexto - Revista do Programa de Pós-Graduação em Controladoria e Contabilidade da UFRGS, v. 15, n. 29, p. 30-46, 2015.

RAUPP, F. M.; PINHO, J. A. G. Prestação de contas nos portais eletrônicos de Assembleias Legislativas: um estudo após a Lei de Acesso à Informação. Revista Gestão \& Planejamento, v. 15, n. 1, p. 144-161, 2014.

REIS, E. M. S. Transparência das contas públicas: uma análise nos portais de transparência dos municípios da região Sul Fluminense. 2016. Trabalho de Conclusão de Curso - Universidade Federal Fluminense, Volta Redonda.

SANTOS, P. M.; BERNARDES, M. B.; ROVER, A. J. Teoria e prática de governo aberto: lei de acesso à informação nos executivos municipais da região sul. Florianópolis: Fundação Boiteux, p. 19, 2012.

SMANIO, G. P.; NUNES, A. R. S. Transparência e controle social de políticas públicas: efetivação da cidadania e contribuição ao desenvolvimento. Interfaces Científicas Humanas e Sociais, Aracaju, v.4, n.3, p. 83-96, 2016. Disponivel em: <https://periodicos.set.edu.br/index.php/humanas/article/view/2844>. Acesso em: 17 de dez de 2017. 